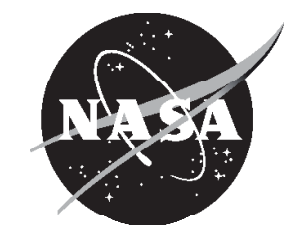

\title{
Volume Dynamics Propulsion System Modeling for Supersonics Vehicle Research
}

George Kopasakis, Joseph W. Connolly, and Daniel E. Paxson

Glenn Research Center, Cleveland, Ohio

Peter Ma

University of Florida, Gainesville, Florida 


\section{NASA STI Program . . . in Profile}

Since its founding, NASA has been dedicated to the advancement of aeronautics and space science. The NASA Scientific and Technical Information (STI) program plays a key part in helping NASA maintain this important role.

The NASA STI Program operates under the auspices of the Agency Chief Information Officer. It collects, organizes, provides for archiving, and disseminates NASA's STI. The NASA STI program provides access to the NASA Aeronautics and Space Database and its public interface, the NASA Technical Reports Server, thus providing one of the largest collections of aeronautical and space science STI in the world. Results are published in both non-NASA channels and by NASA in the NASA STI Report Series, which includes the following report types:

- TECHNICAL PUBLICATION. Reports of completed research or a major significant phase of research that present the results of NASA programs and include extensive data or theoretical analysis. Includes compilations of significant scientific and technical data and information deemed to be of continuing reference value. NASA counterpart of peer-reviewed formal professional papers but has less stringent limitations on manuscript length and extent of graphic presentations.

- TECHNICAL MEMORANDUM. Scientific and technical findings that are preliminary or of specialized interest, e.g., quick release reports, working papers, and bibliographies that contain minimal annotation. Does not contain extensive analysis.

- CONTRACTOR REPORT. Scientific and technical findings by NASA-sponsored contractors and grantees.

- CONFERENCE PUBLICATION. Collected papers from scientific and technical conferences, symposia, seminars, or other meetings sponsored or cosponsored by NASA.

- SPECIAL PUBLICATION. Scientific, technical, or historical information from NASA programs, projects, and missions, often concerned with subjects having substantial public interest.

- TECHNICAL TRANSLATION. Englishlanguage translations of foreign scientific and technical material pertinent to NASA's mission.

Specialized services also include creating custom thesauri, building customized databases, organizing and publishing research results.

For more information about the NASA STI program, see the following:

- Access the NASA STI program home page at http://www.sti.nasa.gov

- E-mail your question via the Internet to help@ sti.nasa.gov

- Fax your question to the NASA STI Help Desk at 301-621-0134

- Telephone the NASA STI Help Desk at 301-621-0390

- Write to: NASA Center for AeroSpace Information (CASI) 7115 Standard Drive Hanover, MD 21076-1320 


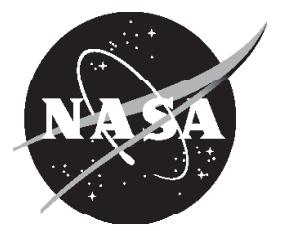

\section{Volume Dynamics Propulsion System Modeling for Supersonics Vehicle Research}

George Kopasakis, Joseph W. Connolly, and Daniel E. Paxson

Glenn Research Center, Cleveland, Ohio

Peter Ma

University of Florida, Gainesville, Florida

Prepared for the

Turbo Expo 2008 Gas Turbine Technical Congress and Exposition sponsored by the American Society of Mechanical Engineers

Berlin, Germany, June 9-13, 2008

National Aeronautics and

Space Administration

Glenn Research Center

Cleveland, Ohio 44135 


\section{Acknowledgments}

The authors would like to acknowledge Kevin J. Melcher and Clarence T. Chang from NASA Glenn for helpful discussions in the course of developing this model.

Trade names and trademarks are used in this report for identification only. Their usage does not constitute an official endorsement, either expressed or implied, by the National Aeronautics and Space Administration.

This work was sponsored by the Fundamental Aeronautics Program at the NASA Glenn Research Center.

Level of Review: This material has been technically reviewed by technical management.

Available from

NASA Center for Aerospace Information 7115 Standard Drive

Hanover, MD 21076-1320
National Technical Information Service 5285 Port Royal Road Springfield, VA 22161

Available electronically at http://gltrs.grc.nasa.gov 


\title{
Volume Dynamics Propulsion System Modeling For Supersonics Vehicle Research
}

\author{
George Kopasakis, Joseph W. Connolly, and Daniel E. Paxson \\ National Aeronautics and Space Administration \\ Glenn Research Center \\ Cleveland, Ohio 44135 \\ Peter Ma \\ University of Florida \\ Gainesville, Florida 32611
}

\begin{abstract}
Under the NASA Fundamental Aeronautics Program the Supersonics Project is working to overcome the obstacles to supersonic commercial flight. The proposed vehicles are long slim body aircraft with pronounced aero-servo-elastic modes. These modes can potentially couple with propulsion system dynamics; leading to performance challenges such as aircraft ride quality and stability. Other disturbances upstream of the engine generated from atmospheric wind gusts, angle of attack, and yaw can have similar effects. In addition, for optimal propulsion system performance, normal inlet-engine operations are required to be closer to compressor stall and inlet unstart. To study these phenomena an integrated model is needed that includes both airframe structural dynamics as well as the propulsion system dynamics. This paper covers the propulsion system component volume dynamics modeling of a turbojet engine that will be used for an integrated vehicle Aero-Propulso-Servo-Elastic model and for propulsion efficiency studies.
\end{abstract}

\section{Nomenclature}

$\begin{array}{ll}A & \text { area, } \mathrm{m}^{2} \\ c_{p} & \text { specific heat at constant pressure, } \mathrm{J} /(\mathrm{kg} * \mathrm{~K}) \\ c_{v} & \text { specific heat at constant volume, } \mathrm{J} /\left(\mathrm{kg}^{*} \mathrm{~K}\right. \\ \mathrm{F} & \text { thrust, } \mathrm{N} \\ g & \text { gravitational constant, } 1\left(\mathrm{~kg}^{*} \mathrm{~m}\right) /\left(\mathrm{N}^{*} \mathrm{sec}^{2}\right) \\ \mathrm{h} & \text { static enthalpy, } \mathrm{J} / \mathrm{kg} \\ I & \text { moment of inertial, }(\mathrm{N} * \mathrm{~m}) / \mathrm{sec}^{2} \\ J & \text { mechanical equivalent of heat, } 1\left(\mathrm{~N}^{*} \mathrm{~m}\right) / \mathrm{J} \\ K_{A}, K_{B} & \text { combustor coefficients, unit less } \\ K_{C} & \text { combustor coefficients, }\left(\mathrm{N}^{2} * \mathrm{sec}^{2}\right) /\left(\mathrm{kg}^{2} * \mathrm{~m}{ }^{4} * \mathrm{~K}\right) \\ K_{b} & \text { bleed flow coefficient, }\left(\mathrm{kg}^{*} \mathrm{~K}^{1 / 2}\right) /\left(\mathrm{N}^{*} \mathrm{sec}\right) \\ K_{n o z} & \text { nozzle parameter, }\left(\mathrm{kg} \mathrm{m}^{2} * \mathrm{~K}^{1 / 2}\right) /\left(\mathrm{N}^{*} \mathrm{sec}\right) \\ l & \text { length, m } \\ M & \text { mach number } \\ M_{\text {air }} & \text { molecular weight of air, } 0.02897(\mathrm{~kg} / \mathrm{mol}) \\ M_{f u e l} & \text { molecular weight of fuel }(\mathrm{JP}-4), 0.139(\mathrm{~kg} / \mathrm{mol}) \\ M_{c a} & \text { molecular weight of cooling air, } 0.02897(\mathrm{~kg} / \mathrm{mol}) \\ N & \text { rotational speed, rpm } \\ N_{c} & \text { corrected speed ratio } \\ P & \text { pressure, N/m }\end{array}$

$\begin{array}{ll}R & \text { universal gas constant, } 287(\mathrm{~N} * \mathrm{~m}) /\left(\mathrm{kg}^{*} \mathrm{~K}\right) \\ r & \text { rotor mean radius, } \mathrm{m} \\ r_{T} & \text { rotor tip radius, } \mathrm{m} \\ T & \text { temperature, } \mathrm{K} \\ U & \text { velocity, } \mathrm{m} / \mathrm{sec} \\ U_{a b} & \text { volumetric flow rate of combustor air, } \mathrm{m} / \mathrm{sec} \\ V & \text { volume, } \mathrm{m}^{3} \\ \dot{W} & \text { mass flow rate, } \mathrm{kg} / \mathrm{sec} \\ \dot{W}_{. c m f} & \text { corrected mass flow rate, } \mathrm{kg} / \mathrm{sec} \\ W_{f}^{\prime \prime} & \text { externally acted upon fuel flow, } \mathrm{kg} / \mathrm{sec}\end{array}$

\section{Greek}

$\gamma \quad$ ratio of specific heats, $\gamma_{c p}=1.4, \gamma_{c b}=\gamma_{t b}=\gamma_{a b}=1.31$

$\eta \quad$ efficiency

$\Theta \quad$ molecular vibration energy constant associated with a gas mixture, $\mathrm{K}$

$\rho \quad$ weight density, $\mathrm{kg} / \mathrm{m}^{3}$

$\tau \quad$ delay time

$\tau_{t} \quad$ delay time associated with fuel transport and mixing

$\phi \quad$ fuel to air ratio

\section{Subscripts}

a variable associated with combustor acoustics

$a b \quad$ variable associated with the afterburner

$a m b \quad$ variable associated with ambient conditions

$b \quad$ variable associated with compressor bleed

c variable associated with stage characteristics

ca variable associated with cooling air

$c b \quad$ variable associated with the combustor

$c p \quad$ variable associated with the compressor

$d \quad$ variable associated with designed value

$e \quad$ variable associated with engine exit condition

$f \quad$ variable associated with fuel

$f l \quad$ variable associated with flame dynamics

$i \quad$ index associated with nozzle volume element number

$j \quad$ index associated with turbine stage number

$k \quad$ number of compressor stages

$l \quad$ index associated with inlet volume element number

$m \quad$ number of turbine stages

$n \quad$ index associated with compressor stage number

noz variable associated with the nozzle 
$o \quad$ variable associated with engine entrance condition

$q \quad$ number of inlet volume elements

perf variable associated with a thermally perfect gas

ref variable associated with reference value

$t b \quad$ variable associated with the turbine

$s \quad$ static condition

$s v \quad$ static condition variable associated with stage volume

tc total condition variable associated with stage characteristics

$t v$ total condition variable associated with stage volume

$z \quad$ variable associated with nozzle

\section{Introduction}

In many aero-propulsion applications a relatively low fidelity engine model (i.e., without volume dynamics), which includes speed and temperature dynamics with the appropriate component performance characteristics is adequate to design control laws. The actuation system, such as fuel actuation, is rather slow and as a result the control bandwidth is reduced, which makes such lower fidelity simulations (refs. 1 and 2) appropriate for controls design. In supersonics, the slim body structure of the vehicle excites structural dynamics, which can introduce upstream flow field disturbances at higher frequencies (up to $50 \mathrm{~Hz}$ or more). The vehicle control surfaces are actuated to suppress some of these structural modes associated with flutter (refs. 3 and 4).

Analysis needs to be carried out to understand how these aeroservo-elastic (ASE) excitations as well as other atmospheric disturbances impact the propulsion system in terms of thrust variations that can affect ride quality and vehicle stability. In addition, the coupling of the propulsion system to the vehicle ASE modes needs to be analyzed, and for that an integrated aeropropulso-servo-elastic system (APSE) simulation is needed. Due to the high frequencies of these modes the propulsion system simulation needs to incorporate 1D volume dynamics based on conservation equations modeling.

A propulsion system for a supersonic vehicle also differs from a conventional vehicle in that a supersonic vehicle utilizes a supersonic inlet with active controls for shock positioning, which can also excite higher frequency dynamics. In addition, how these upstream disturbances impact the inlet shock positioning, pressure recovery, as well as inlet distortion and its impact on thrust variations also needs to be analyzed. Also to achieve high performance, a supersonic vehicle would operate closer to compressor stall and inlet unstart. This necessitates modeling utilizing component volume dynamics in order to study the dynamic interaction of these engine components. This paper covers the propulsion system component volume dynamics modeling of a turbojet engine. The supersonic inlet dynamics and their effect on the rest of the propulsion system and the vehicle will be addressed in some future studies.

The propulsion system simulation described in this paper uses the architecture of a J85-13 turbojet engine; although it can be adapted to simulate different engines due to its generic architecture. The development of this engine simulation in MATLAB SIMULINK $^{\circledR}$ is partially based on a simulation developed years ago at NASA Glenn Research Center (GRC) (ref. 5), using an analog computer and also referred herein as the Seldner simulation. In the engine simulation described here, some of the geometries are approximated, and the component performance maps are generic. The Seldner simulation was verified in both steady-state and dynamic modes by comparing analytical results with experimental data obtained from tests performed at GRC with a J85-13 engine. The simulation described in this paper has been verified by comparing it against simulation results provided in Seldner (ref. 5), and also from simulations that display expected engine responses based on experience.

The engine model presented is based on stage-by-stage component volume dynamics. The simulation results presented are based on component level volume dynamics. The component level volume dynamics model of the engine is envisioned to be a stepping stone towards eventually obtaining a stage-by-stage model with all the appropriate stage performance maps that may be required to address the thrust variations issue.

The paper is organized as follows. First, the engine dynamic model development is described in detail for each major component. This is followed by some simulation results to help verify the engine simulation, as well some preliminary thrust variation studies. Finally, future plans for upgrading the engine model, including plans for additional analysis and controls design are discussed, followed by concluding remarks.

\section{Engine Model}

The Seldner (ref. 5) simulation technique was applied to the J85-13 engine. The simulation developed herein is also applied to the J85-13 engine, with some assumed component performances and geometries. The J85-13, shown in figure 1 is an afterburning, turbojet engine with an eight-stage axial-flow compressor and a two stage turbine. Compressor discharge air that bypasses the combustion zone is used to cool combustor and turbine components. The engine also has variable inlet guide vanes, controlled interstage bleeds, and a variable-area exhaust nozzle. The modeling approach described herein is generic. But the reason this engine was chosen is that some information and simulation results about this engine are available, and also because this engine architecture is closer to an engine architecture that is expected to be used for a supersonic vehicle.

The engine simulation incorporates component performances in the form of performance maps for the compressor and turbine along with component volume dynamics. The modeling approach follows the basic approach discussed in reference 5 for the J85-13 engine simulation, developed utilizing an analog computer. Differences in the modeling approach are noted in the upcoming sections of this paper that cover component simulations. Some of the pertinent component performance maps and geometry properties of the engine were not recorded in reference 5. Therefore, some assumptions are made in developing this simulation. The simulation is verified against steady state experimental results and some dynamic responses available in reference 5 . The simulation described in reference 5 covers stage-by-stage control volume dynamics, while the actual 


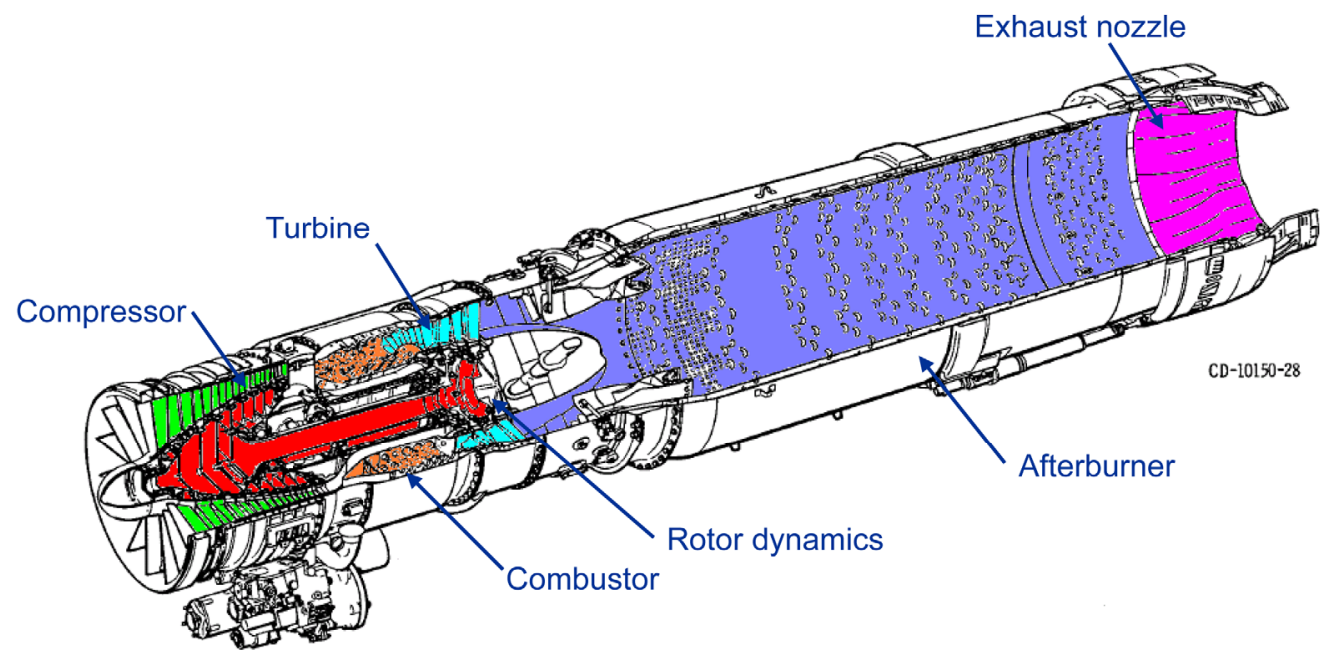

Figure 1.-J85-13 engine.

simulation here is incorporated with component level lumped volume dynamics, and therefore, there could be some differences in dynamic responses.

\section{Compressor}

This section describes the compressor model based on the individual compressor stages. In reference 5 the compressor maps were expressed in terms of normalized coefficients of pressure and temperature versus flow. Because it is rare at present to find performance maps expressed in these terms, a map generation routine is used to derive overall compressor maps in a more conventional form consisting of the pressure ratio versus corrected mass flow rate and compressor efficiency versus pressure ratio. The compressor maps would normally differ for inlet guide vane position and bleed flow. Certain geometrical properties of the compressor like cross section area, length, mean radius, and tip radius are not available and are estimated.

For a stage-by-stage compressor model, the individual compressor stage characteristics are needed. This includes computing the pressure and temperature rise across each stage, by representing each stage with a pair of pressure and temperature (efficiency) maps, followed by its appropriate stage volume. Based on such an approach, the compressor consists of interconnected stages, stacked together to form the overall compressor model. An idealized compressor stage is shown in figure 2.

The gas dynamics associated by applying continuity, momentum, and energy to a compressor stage, are

$$
\begin{gathered}
\frac{d}{d t} \rho_{s v, n}=\frac{1}{V_{n}}\left(\dot{W}_{c, n}-\dot{W}_{c, n+1}-\dot{W}_{b, n}\right) \\
\frac{d}{d t} \dot{W}_{c, n}=\frac{A_{n} g}{l_{n}}\left(P_{t c, n}-P_{t v, n}\right)\left(1+\frac{\gamma_{c p}-1}{2} M_{n}^{2}\right)^{-\frac{\gamma_{c p}}{\gamma_{c p}-1}}
\end{gathered}
$$

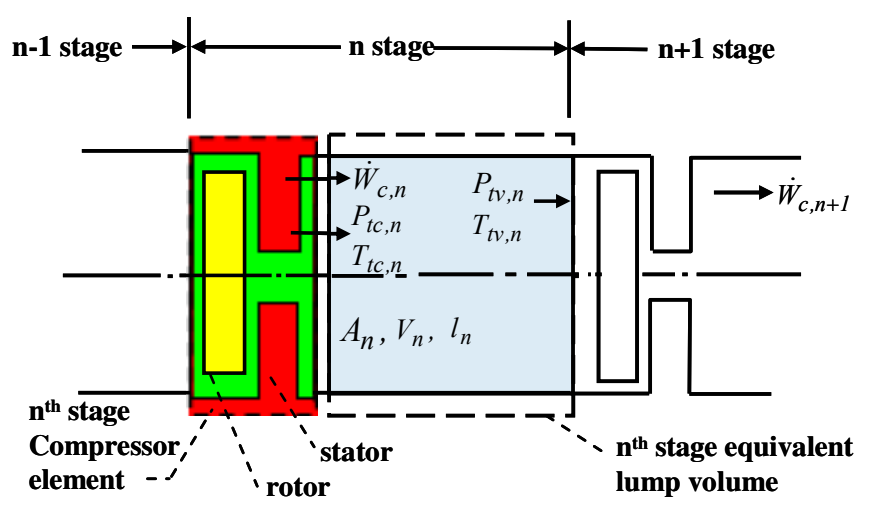

Figure 2.-Schematic of $\mathrm{n}^{\text {th }}$ compressor stage.

$$
\frac{d}{d t} T_{t v, n}=\frac{\gamma_{c p}}{\rho_{s v, n} V_{n}}\left(T_{t c, n} \dot{W}_{c, n}-T_{t v, n} \dot{W}_{c, n+1}-T_{t v, n} \dot{W}_{b, n}\right)
$$

where total temperature and pressure conditions at the compressor first stage and inlet exit are equivalent $\left(T_{t c, n=l}=T_{t, l=q}\right.$ and $\left.P_{t c, n=1}=P_{t, l=q}\right)$, and mass flow at the compressor exit and combustor inlet are equivalent $\left(W_{c, n=k+1}=W_{c b}\right)$. The equation of state for the $\mathrm{n}^{\text {th }}$ stage volume, for $\mathrm{k}$ number of stages, is

$$
P_{t v, n}=\left(1+\frac{\gamma_{c p}-1}{2} M_{n}{ }^{2}\right)^{\frac{1}{\gamma_{c p}-1}} \rho_{s v, n} R T_{t v, n}
$$

The correction factors involving Mach number and gamma in eq. (2) and (4) are inserted to correct for the differences between static and total conditions. If these corrections are not made, the steady-state accuracy of the simulation will not be impacted, but dynamically the error can be up to $15 \%$. The stage Mach number is 


$$
M_{n}=\frac{\dot{W}_{c, n}}{\rho_{s v, n} A_{n} \sqrt{\gamma_{c p} R T_{s, n}}}
$$

where

$$
T_{s, n}=T_{t v, n}-\frac{\dot{W}_{c, n}^{2}}{2 \rho_{s v, n}^{2} A_{n}^{2} c_{p, n}}
$$

Bleed flow is extracted from some of the compressor stages. The bleed flow relation assumes choked flow conditions, were $K_{b}$, is the portion of the bleed flow effective area.

$$
\dot{W}_{b, n}=K_{b} A_{b, n} \frac{P_{t v, n}}{\sqrt{T_{t v, n}}}
$$

The overall compressor performance maps are shown in figure 3 and figure 4. For stage-by-stage modeling, individual stage maps should be utilized instead. The corrected mass flow rate is shown in figure 3 . If this is the map for the $n^{\text {th }}$ stage, the corrected parameters are computed as

$$
\dot{W}_{c m f, n}=\frac{W_{c, n} \sqrt{T_{t v, n-1} / T_{r e f}}}{P_{t v, n-1} / P_{r e f}}
$$

Similarly, the corrected speed ratio used in figure 3 and figure 4 is computed as

$$
N_{c, n}=\frac{N}{N_{d, n}} \sqrt{T_{d, n} / T_{t v, n-1}}
$$

The corrected mass flow rate and corrected speed are used to find the pressure ratio in figure 3 , and the pressure ratio and corrected speed are used to find the efficiency in figure 4 . From the pressure ratio, $P_{r, n}$, the stage total pressure can be computed as

$$
P_{t c, n}=P_{r, n} * P_{t v, n-1}
$$

From the efficiency ratio and the pressure ratio, the stage total temperature can be computed as

$$
T_{t c, n}=T_{t v, n-1}\left[1+\frac{P_{r, n}^{\left(\gamma_{c p}-1\right) / \gamma_{c p}}-1}{\eta_{c p}}\right]
$$

The cross section area in eqs. (2), (5) and (6) is

$$
A_{n}=4 \pi r_{n}\left(r_{T n}-r_{n}\right)
$$

The differences between the model presented here and the one from reference 5 are as follows. First, in reference 5, correction factor approximations are given for the momentum and the state equations but are not utilized in the simulation. Instead, in this development exact relationships are provided.

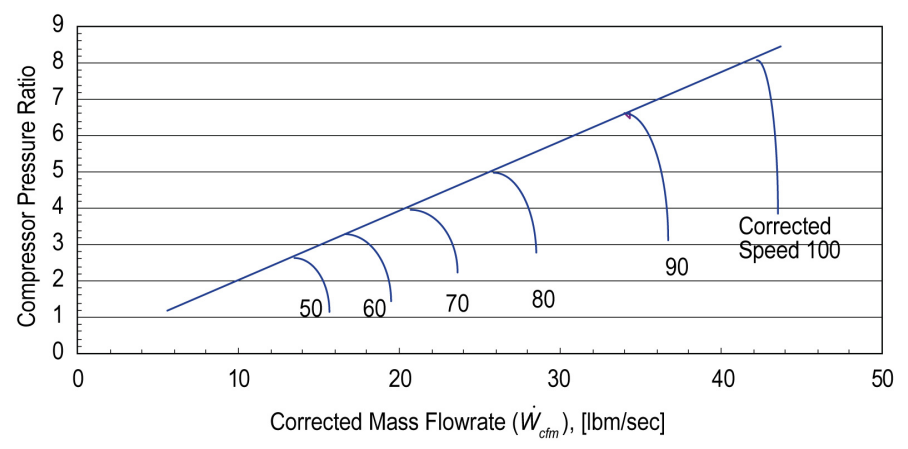

Figure 3.-Overall compressor pressure ratio map.

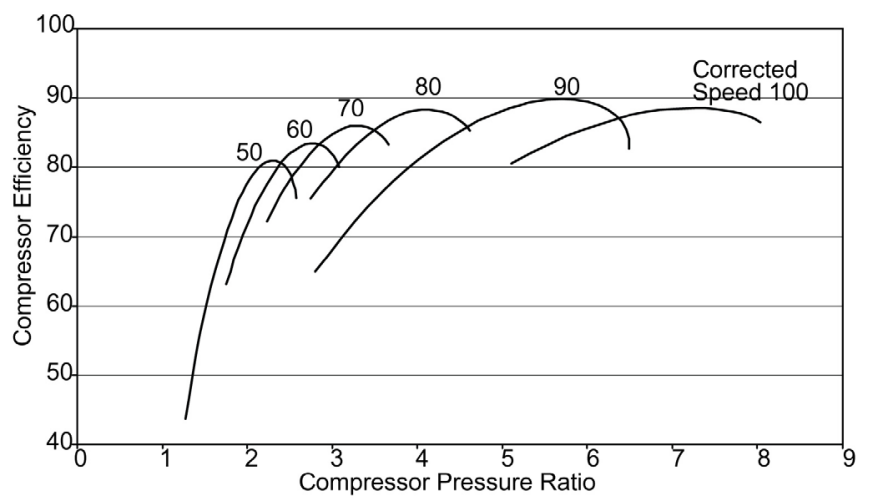

Figure 4.-Overall compressor efficiency map.

Second, the compressor maps are presented here in terms of pressure ratios and efficiency, instead, of flow coefficients that were utilized in reference 5 . Third, based on these changes, all the pertinent mathematical relations for the Mach number and the corrected map quantities are provided in eqs. (5) to (11), including the cross section area calculation which is provided in eq. (12).

Equations (1) to (12) represent the stage modeling of the compressor. In the absence of individual stage maps, the root of the number of stages of the compressor pressure ratio and efficiency ratio (i.e., the parameter raised to the power of $1 / \mathrm{n}$ ) could serve as a rough approximation. However, the accuracy of the compressor and turbine simulations results and stability could depend on the accuracy of the stage or component performance and geometries. Stacking the stages together and with the individual stage performance maps, the compressor model is complete.

\section{Combustor}

The combustor is lumped into a single equivalent onedimensional volume. In this volume the fuel flow combustion dynamics are also added.

The combustor geometry is chosen to represent a lean burning combustor, which is more appropriate for future combustors. Typically, in a behavior type model of lean burning 
combustors (ref. 6), the combustion dynamics can be modeled as a self excitation system of a first order transfer function (TF) representing the flame dynamics, with a second order undamped TF representing the acoustics. But the acoustics here are represented with a first order TF. The assumption is that the unsteady combustion typical to lean burning combustors will be mitigated by some control approach like the one described in (ref. 6). The total combustion time delay is the sum of the delays of fuel transport and mixing, the flame dynamics, and the acoustics as

$$
\tau_{c b}=\tau_{t}+\tau_{f l}+\tau_{a}
$$

Given a combustor volume, $V_{c b}$, and a volumetric flow rate through the combustor, $U_{c b}$, the combustor time delay can be approximated as

$$
\tau_{c b}=V_{c b} / U_{c b}
$$

The total combustion time delay is assumed to be in the order of $5 \mathrm{msec}$, with the fuel transport and mixing time delay accounting for the greater part of this delay. The overall fuel flow combustion dynamics are modeled as follows

$$
\frac{\dot{W}_{f}^{\prime \prime}}{\dot{W}_{f}}=\frac{K e^{-\tau_{t} s}}{\left(\tau_{f l} s+1\right)\left(\tau_{a} s+1\right)}
$$

where $K$ is a proportional TF gain, set to one.

The combustor gas dynamics for continuity, momentum, and energy are

$$
\begin{gathered}
\frac{d}{d t} \rho_{s, c b}=\frac{1}{V_{c b}}\left(\dot{W}_{c b}+\dot{W}_{f}^{\prime \prime}-\dot{W}_{c, j=1}\right) \\
\frac{d}{d t} \dot{W}_{c b}=\frac{A_{c b} g}{l_{c b}}\left(P_{t v, n=k}-P_{t, c b}-\Delta P_{t, c b}\right) \\
\frac{d}{d t} T_{t, c b}=\frac{\gamma_{c b}}{\rho_{s, c b} V_{c b}}\left(T_{t v, n=k} \dot{W}_{c b}+\dot{W}_{f}^{\prime \prime} T_{t, c b}-T_{t, c b} \dot{W}_{c, j=1}\right. \\
\left.+\frac{\eta_{c b}}{c_{p, c b}} \dot{W}_{f}^{\prime \prime} h_{c, c b}\right)
\end{gathered}
$$

and the equation of state is

$$
\begin{gathered}
P_{t, c b}=\rho_{s, c b} R_{c b} T_{t, c b} \\
R_{c b}=\frac{R}{(1-\phi) M_{\text {air }}+\phi M_{\text {fuel }}}
\end{gathered}
$$

where a fuel/air ratio, $\phi$, of about 0.02 was used that represents lean type combustion. Unlike the compressor, correction fac- tors are not used in the combustor simulation due to the low Mach number in the combustor, which makes a negligible difference. The $c_{p}$ value in eq. (18) is not constant in the upper temperature range of the combustor, and for more accurate calculations eq. (44) that is provided later can be used.

In this development, $h_{c}$ was assumed to be a constant of $42.8 \mathrm{e} 6[\mathrm{~J} / \mathrm{kg}]$ for JP-4 fuel, at about $1000 \mathrm{~K}$ (ref. 7). The combustor efficiency map (ref. 5), is shown in figure 5, where

$$
\Delta T_{t, c b}=T_{t, c b}-T_{t v, n=k}
$$

The pressure drop across the combustor is

$$
\Delta P_{t, c b}=\frac{K_{C} \dot{W}_{c b}^{2}}{P_{t v, n=k}}\left(K_{A} T_{t v, n=k}+K_{B} T_{t, c b}\right)
$$

where $K_{A}$ and $K_{B}$ are experimentally determined; $K_{A}$ is found from non-combustion flow tests; $K_{B}$ from combustion flow test. The proportionality constant, $K_{C}$, is found by solving eq. (22) for $K_{C}$, given the designed steady-state quantities in eq. (22) at different speeds. A table is provided in reference 5 for these values. Typical values for $\Delta \mathrm{P}_{t, c b}$ range from 0.05 to 0.1 . In reference $5, K_{C}$ has the same units as $K_{A}$ and $K_{B}$, but $K_{A}$ and $K_{B}$ should be dimensionless.

The differences between the combustor model presented here and the Seldner model, reference 5, are as follows. First, the time delays in eqs. (13) to (15) are chosen for lean burning combustors and the relation of the overall combustor time delay, eq. (14), is provided here. Second, the equation of state is given here, where the specific gas constant is formulated for the combustion mixture. Third, the enthalpy, $h_{c}$, was used as a constant here of about $1000 \mathrm{~K}$. In the Seldner model, $h_{c}$ was determined using stage characteristics with the independent variable $T_{t, c b}$. Fourth, a correction is made to eq. (22) here that involves $W_{c b}$ computed from the combustor volume dynamics instead of the mass flow rate coming from the compressor.

Equations (13) through (22) complete the combustor model.

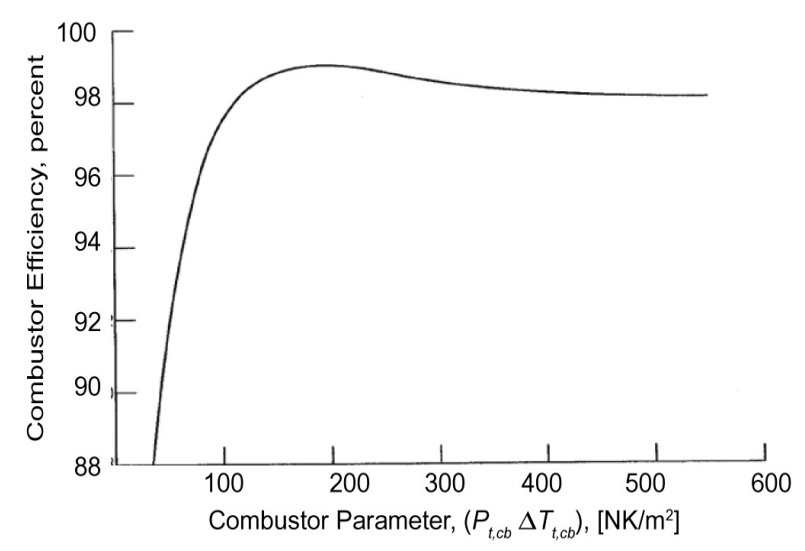

Figure 5.-Combustor efficiency representation. 


\section{Turbine}

In the Seldner model, reference 5, the entire turbine is modeled as a single lumped volume. Moreover, the turbine is combined with the non-combusting afterburner and the nozzle. This combined model was the result of having the turbine contributing to the energy conservation through the enthalpy change, the afterburner contributing to the momentum by dominating the total volume, and both the turbine and the afterburner sharing the continuity equation, with the nozzle governed by compressible flow and choked flow conditions. While the model in reference 5 may exhibit sufficient steadystate accuracy, it's not anticipated that dynamically the frequencies of these components will be accurately represented. Therefore, the turbine and the subsequent afterburner models are different than those presented in reference 5.

An idealized turbine stage would be similar to the compressor stage shown in figure 2 . The gas dynamics associated by applying continuity, momentum, and energy to a turbine stage are

$$
\begin{gathered}
\frac{d}{d t} \rho_{s v, j}=\frac{1}{V_{j}}\left(\dot{W}_{c, j}+\dot{W}_{c a}-\dot{W}_{c, j+1}\right) \\
\frac{d}{d t} \dot{W}_{c, j}=\frac{A_{j} g}{l_{j}}\left(P_{t c, j}-P_{t v, j}\right)\left(1+\frac{\gamma_{t b}-1}{2} M_{j}^{2}\right)^{-\frac{\gamma_{t b}}{\gamma_{t b}-1}} \\
\frac{d}{d t} T_{t v, j}=\frac{\gamma_{t b}}{\rho_{s v, j} V_{j}}\left(T_{t c, j} \dot{W}_{c, j}+T_{t, c a} \dot{W}_{c a, j}-T_{t v, j} \dot{W}_{c, j+1}\right)
\end{gathered}
$$

where total temperature and pressure conditions at the turbine first stage and combustor exit are equivalent $\left(T_{t c, j=1}=T_{t, c b}\right.$ and $\left.P_{t c, j=I}=P_{t, c b}\right)$, and mass flow at the turbine exit and afterburner inlet are equivalent $\left(\dot{W}_{c, j=m+1}=\dot{W}_{a b}\right)$. The equation of state for the $j^{\text {th }}$ stage volume is (for $\mathrm{m}$-number of stages)

$$
P_{t v, j}=\left(1+\frac{\gamma_{t b}-1}{2} M_{j}^{2}\right)^{\frac{1}{\gamma_{t b^{-1}}}} \rho_{s v, n} R_{t b} T_{t v, n}
$$

where

$$
R_{t b}=\frac{R}{(1-\phi)\left(M_{\text {air }}+M_{c a}\right)+\phi M_{f u e l}}
$$

and

$$
\begin{aligned}
& M_{j}=\frac{\dot{W}_{c, j}}{\rho_{s v, j} A_{j} \sqrt{\gamma_{t b} R_{t b} T_{s, j}}} \\
& T_{s, j}=T_{t v, j}-\frac{\dot{W}_{c, j}^{2}}{2 \rho_{s v, j}^{2} A_{j}^{2} c_{p, j}}
\end{aligned}
$$

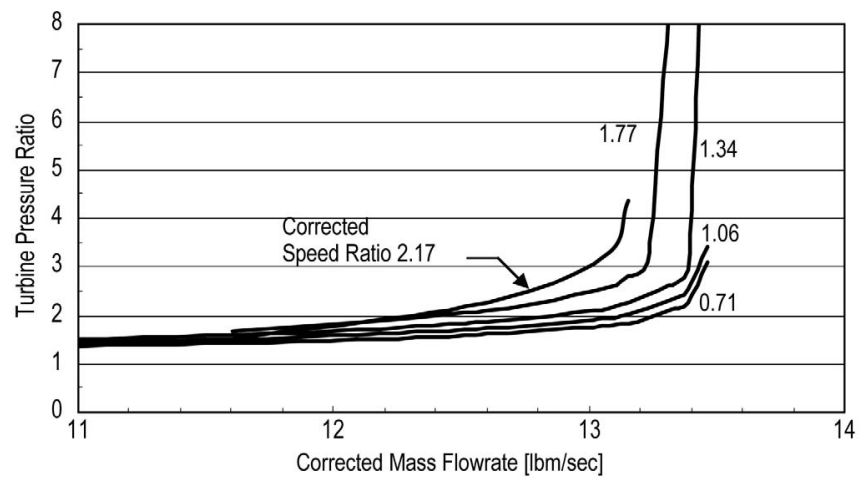

Figure 6.-Overall turbine pressure ratio map.

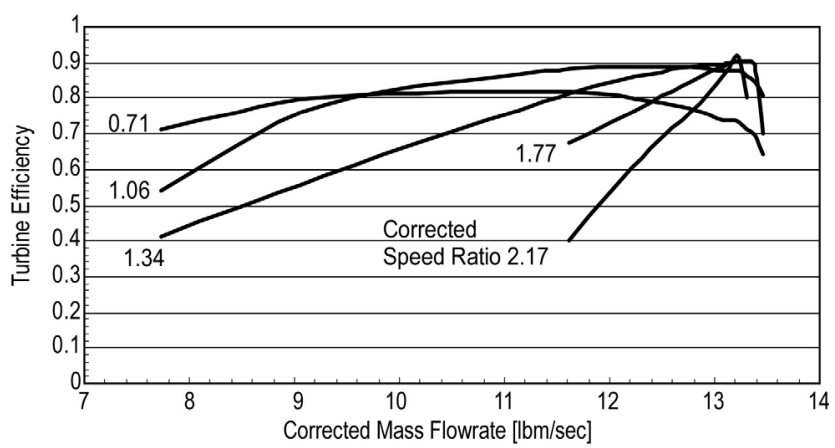

Figure 7.-Overall turbine efficiency map.

The $c_{p}$ value in eq. (29) is not constant in the upper temperature range of the turbine, and for more accurate calculations eq. (44) that is provided later can be used.

Performance maps are incorporated in this development that are more readily available, such as the ones shown in figure 6 and figure 7 for the overall turbine pressure ratio and efficiency.

The corrected mass flow rate and speed ratio are used in figure 6 and figure 7 . If these are the maps for the $j^{\text {th }}$ stage, the corrected parameters would be computed as

$$
\begin{gathered}
\dot{W}_{c m f, j}=\frac{W_{c, j} \sqrt{T_{t v, j-1} / T_{r e f}}}{P_{t v, j-1} / P_{r e f}} \\
N_{c, j}=\frac{N}{N_{d, j}} \sqrt{T_{d, j} / T_{t v, j-1}}
\end{gathered}
$$

From the pressure ratio, $P_{r, j}$, the stage total pressure can be computed as

$$
P_{t c, j}=P_{t v, j-1} / P_{r, j}
$$

From the efficiency ratio and the pressure ratio the stage total temperature can be computed as

$$
T_{t c, j}=\frac{1}{T_{t v, j-1}}\left[1-\eta_{t b}\left(1-P_{r, j}^{\frac{\gamma_{t b}-1}{\gamma_{t b}}}\right)\right]^{-1}
$$


The cross section area in eqs. (24), (28) and (29) is

$$
A_{j}=4 \pi r_{j}\left(r_{T j}-r_{j}\right)
$$

Equations (23) to (34) represent the stage modeling of the turbine. Stacking the stages together and with the individual stage performance maps, the turbine model is complete.

\section{Afterburner and Nozzle}

A combined combusting afterburner and exhaust nozzle model is presented here, with the assumption that a supersonic cruise vehicle would likely employ an afterburner. It is assumed here that the large afterburner acts as a large filter, attenuating high frequency upstream disturbances, such that a detailed multi-finite element volume nozzle model will not impact dynamic thrust calculations. With this assumption, in the combined model the afterburner volume dominates. Also, unlike the Seldner model, a combusting afterburner is modeled here, which also allows for temperature changes across the afterburner. Like the Seldner model, the nozzle is considered as a variable area compressible flow passage capable of choking.

Based on these assumptions, and by separating the afterburner from the turbine model as discussed in the turbine section, the gas dynamics associated by applying continuity, momentum, and energy to the afterburner and nozzle are

$$
\begin{gathered}
\frac{d}{d t} \rho_{s, a b}=\frac{1}{V_{a b}}\left(\dot{W}_{a b}+\dot{W}_{f u e l, a b}-\dot{W}_{z}\right) \\
\frac{d}{d t} \dot{W}_{a b}=\frac{A_{a b} g}{l_{a b}}\left(P_{t v, j=m}-P_{t, a b}\right)\left(1+\frac{\gamma_{a b}-1}{2} M_{a b}^{2}\right)^{-\frac{\gamma_{a b}}{\gamma_{a b}-1}} \\
\frac{d}{d t} T_{t, a b}=\frac{\gamma_{a b}}{\rho_{s, a b} V_{a b}}\left(T_{t v, j=m} \dot{W}_{a b}+Q_{a b}-T_{t, a b} \dot{W}_{z}\right)
\end{gathered}
$$

At some future point, the heat addition $Q_{a b}$ will be consisting of two terms, similar to the combustor model. One term will be due to the heat addition of the afterburner fuel, and the other term will be due to the heat addition of the combusted fuel mixture with the associated fuel system dynamics. The equation of state is

$$
P_{t, a b}=\left(1+\frac{\gamma_{a b}-1}{2} M_{a b}^{2}\right)^{\frac{1}{\gamma_{a b}-1}} \rho_{s, a b} R_{a b} T_{t, a b}
$$

where $R_{a b}$ can be calculated similarly to eq. (20). The nozzle, with its mass flow rate, becomes the terminal boundary of the turbojet as

$$
\dot{W}_{z}=\frac{K_{z} P_{t, a b}}{\sqrt{T_{t, a b}}}\left(\frac{P_{s, a m b}}{P_{t, a b}}\right)^{\frac{1}{\gamma_{a b}}} \sqrt{1-\left(\frac{P_{s, a m b}}{P_{t, a b}}\right)^{\frac{\gamma_{a b}-1}{\gamma_{a b}}}}
$$

The second and third multiplicative terms in eq. (39) represent the well known compressible flow function (ref. 5). The parameter $K_{z}$ is variable and proportional to the nozzle area. It represents the turbojet terminal impedance, and lumps the nozzle flow coefficient and nozzle area with other flow parameters. This parameter, through the variable nozzle area, is scheduled as a function of engine speed to match the steadystate operating line. In the simulation, $K_{z}$ was experimentally determined to better match expected results.

Equations (35) to (39) complete the afterburner and the nozzle model.

\section{Rotor Dynamics}

The steady-state performance of a turbojet engine matches the compressor with that of the turbine operating points. A mismatch in these components produces an unbalanced torque or acceleration, which is integrated through the dynamic relations to seek a new steady-state match. The rotor dynamics are based on the changes of mass and enthalpy. Therefore, the change of rotor speed is a function of the energy differential between the work extracted by the turbine and the work done by the compressor a

$$
\begin{aligned}
\frac{d}{d t} N & =\left(\frac{30}{\pi}\right)^{2} \frac{J}{N I}\left[\left(\dot{W}_{c, j=1} h_{c b}+\dot{W}_{c a} h_{c a}-\dot{W}_{a b} h_{j=m}\right)\right. \\
& \left.-\left(\dot{W}_{c, n=k} h_{n=k}+\dot{W}_{b} h_{b}-\dot{W}_{c, n=1} h_{n=1}\right)\right]
\end{aligned}
$$

The enthalpies in eq. (40) can be computed as follows.

$$
\begin{gathered}
h_{c b}=c_{p, c b} T_{t, c b} \\
h_{j}=c_{p, j} T_{t v, j} \\
h_{n}=c_{p, n} T_{t v, n}
\end{gathered}
$$

The specific heat at constant pressure, $c_{p}$, is not constant and it varies as a function of temperature and gas mixture based on the following equation, for a thermally perfect gas.

$c_{p, x}=\left(c_{p}\right)_{\text {perf }}\left\{1+\frac{\gamma_{\text {perf }}-1}{\gamma_{\text {perf }}}\left[\left(\frac{\Theta_{x}}{T_{t, x}}\right)^{2} \frac{e^{\theta_{x} / T_{t, x}}}{\left(e^{\theta_{x} / T_{t, x}}-1\right)^{2}}\right]\right\}$

The combustor and the turbine specific heat vary some in the order of $1000 \mathrm{~K}$. But the specific heat will be different due to the addition of fuel. For a pure air mixture, $\Theta=3056 \mathrm{~K}$.

The differences between the rotor model presented here and the Seldner model, reference 5, are as follows. First, the Seldner model does not take into account the cooling air coming in the turbine. Second, in the Seldner model the enthalpies are not defined, and third, that model assumes a constant specific heat. 


\section{Engine Thrust}

Thrust was not included in the Seldner model, but it is estimated in this model as follows. In general, the net thrust is the sum of the momentum thrust and the pressure thrust as

$$
F=\frac{\dot{W}_{z}}{g}\left(U_{e}-U_{o}\right)+\left(P_{e}-P_{s, a m b}\right) A_{e}
$$

and

$$
P_{e}=P_{t, a b}\left[1+\frac{1-\gamma_{z}}{\eta_{z}\left(1+\gamma_{z}\right)}\right]^{\frac{\gamma_{z}}{\gamma_{z}-1}}
$$

At steady-state, the engine thrust is primarily due to the momentum thrust; the pressure difference in eq. (45) is about zero by scheduling $K_{z}$ (i.e., by adjusting the nozzle exit area) as a function of the speed, $N$. However, in the dynamic sense, for thrust calculations, the pressure thrust in eq. (45) could be significant.

\section{Engine Simulation Results}

In this section, selected results are presented for the whole engine simulation running together at sea level static flight conditions. These are for the component level lumped volume dynamics engine model. All it takes to convert the compressor and turbine models presented earlier into component level lumped volumes is to drop the subscripts that represent the stage-by-stage model and also use the performance maps for the entire component. Some of the initial objectives are to analyze thrust variations and controls designs using the component level lumped volume dynamic model, and later to address whether a more detail model is needed that employs stage-by-stage volume dynamics.

Table 1 shows some steady state comparisons at sea level conditions between the engine, the Seldner simulation, and the model developed in this paper. The simulation results closely depict the engine steady state performance, within a few percent errors. One point worth noting here is that the engine model in this paper employs component maps and geometries that are not the same as the ones used in the Seldner model. Therefore, direct comparison of simulation results is difficult and can only be done in a relative sense. But even that would be challenging because the engine operating conditions that were used to produce these results, for Seldner model, were not fully documented.

TABLE 1.-COMPARISON OF STEADY STATE RESULTS AT SEA LEVEL

\begin{tabular}{|l|c|c|c|c|}
\hline & $\begin{array}{c}\text { Rotor } \\
\text { Speed }\end{array}$ & $\begin{array}{c}\text { Compressor } \\
\text { Massrate }\end{array}$ & $\begin{array}{c}\text { Turbine } \\
\text { Pressure }\end{array}$ & $\begin{array}{c}\text { Turbine } \\
\text { Temp. }\end{array}$ \\
\hline Experimental & $100 \%$ & $19.90[\mathrm{~kg} / \mathrm{sec}]$ & $246,200[\mathrm{~Pa}]$ & $992[\mathrm{~K}]$ \\
\hline Seldner Model & $100 \%$ & $20.00[\mathrm{~kg} / \mathrm{sec}]$ & $264,100[\mathrm{~Pa}]$ & $1021[\mathrm{~K}]$ \\
\hline This Model & $104 \%$ & $20.99[\mathrm{~kg} / \mathrm{sec}]$ & $248,320[\mathrm{~Pa}]$ & $955[\mathrm{~K}]$ \\
\hline $\begin{array}{l}\text { Error (Exp. Vs. } \\
\text { this model) }\end{array}$ & $4.00 \%$ & $5.48 \%$ & $0.86 \%$ & $3.72 \%$ \\
\hline
\end{tabular}

Figure 8 and figure 9 show comparisons of frequency responses from simulation results obtained from the model in this paper and results from the experimental engine published in Seldner's report. These frequency responses show that the magnitudes are about the same, with some variation in the frequency range of 1 to $40 \mathrm{~Hz}$. Also, the dominant frequencies in these responses are nearly the same, in the range of about 35 to $50 \mathrm{~Hz}$. Simulation results from the Seldner model, not shown here, more closely approximate those of the experimental engine. The reason is that the Seldner model matches the experimental engine in terms of geometries and component performance.

Figure 10, figure 11, and figure 12 show engine step responses due to the combustor fuel mass addition, at the same steady state operating point depicted in table 1 . These responses follow trends that would be expected from this engine.

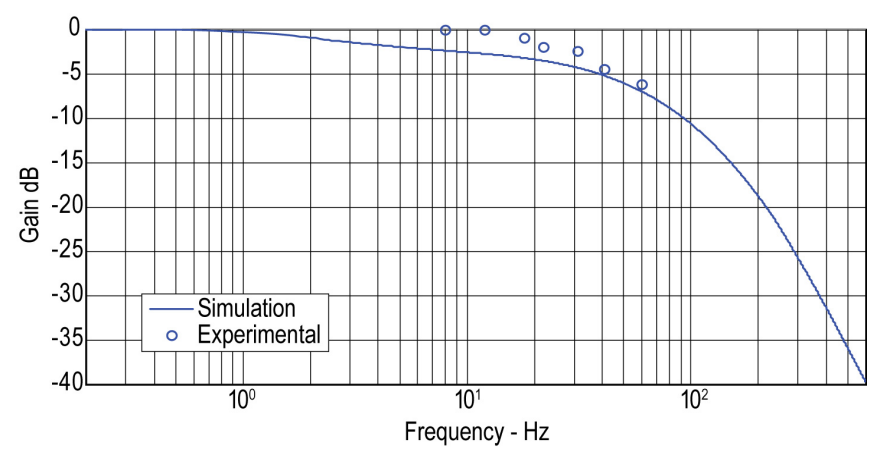

Figure 8.-Comparison of engine simulation and experimental results for compressor pressure due to fuel response.

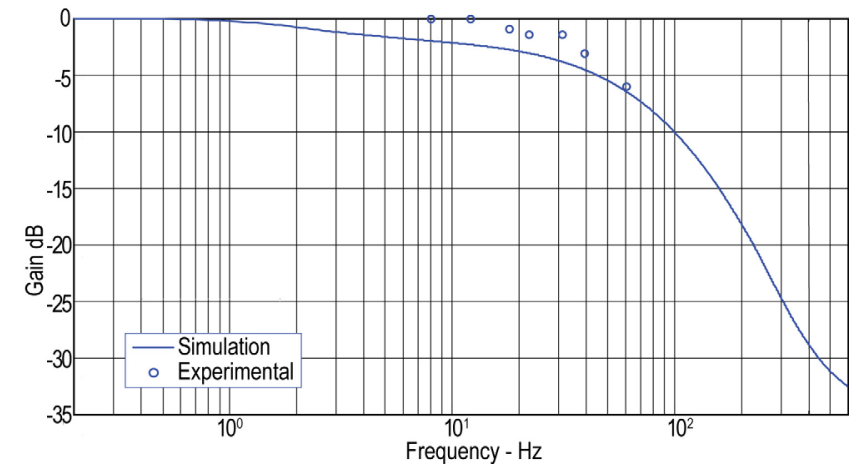

Figure 9.-Comparison of engine simulation and experimental results for combustor pressure due to fuel response.

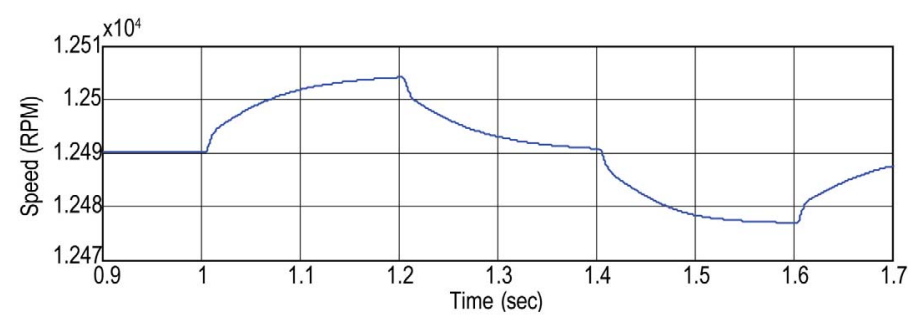

Figure 10.-Step response of engine speed due to fuel. 


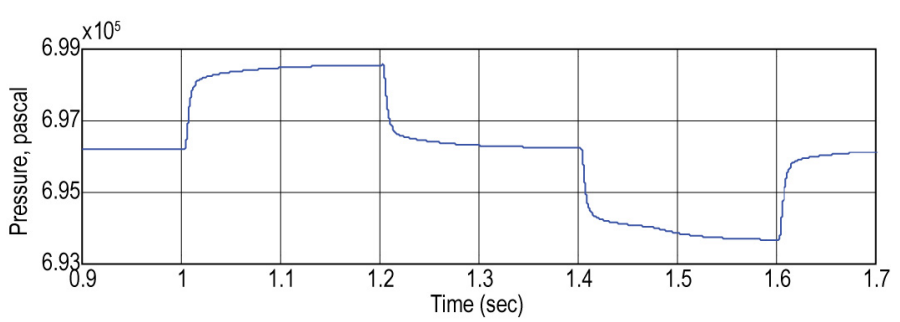

Figure 11.-Step response of combustor pressure to fuel.

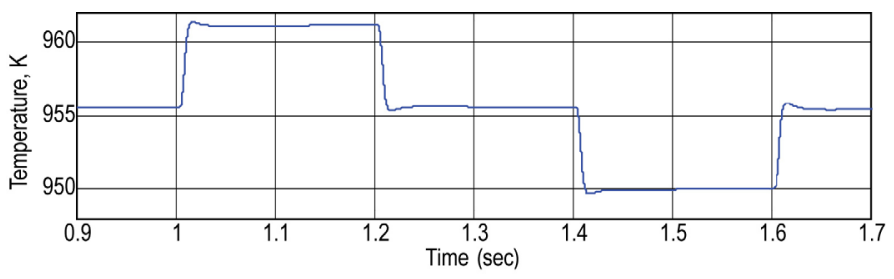

Figure 12.-Step response of turbine temperature to fuel.

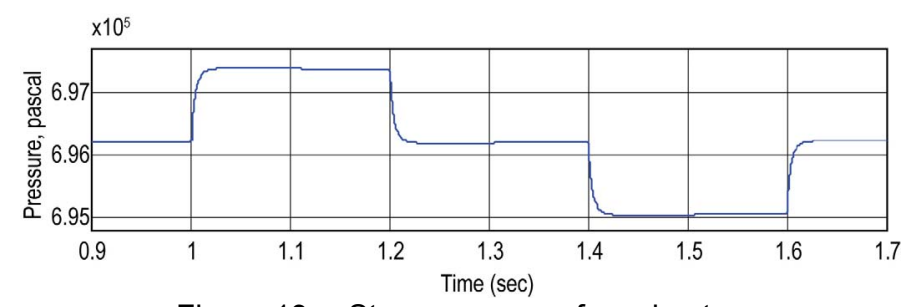

Figure 13.- Step response of combustor pressure to engine input total pressure.

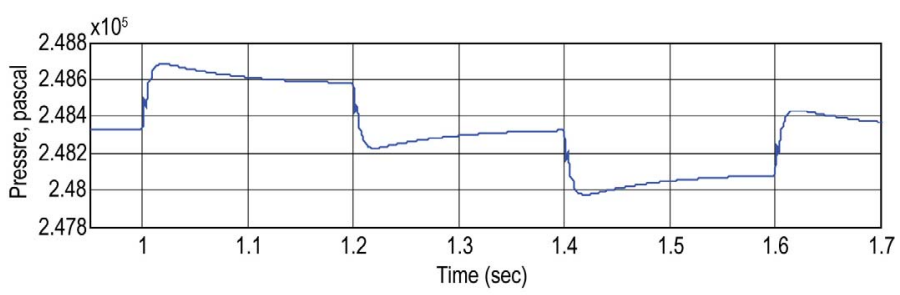

Figure 14.-Step response of turbine total pressure to engine input total pressure.

Figure 13 and figure 14 show engine total pressure step responses due to engine input total pressure at the compressor face, again at the same operating condition as shown in table 1. The input pressure is stepped by $250 \mathrm{~Pa}$, then back to nominal, followed by a $-250 \mathrm{~Pa}$ step, and back to nominal.

Figure 15 and figure 16 show engine total temperature step responses due to $1 \mathrm{~K}$ engine input total temperature steps at the compressor face. These responses also follow expected trends, with the turbine temperature step response being a bit more complicated. It has been observed that the turbine temperature response is rather sensitive to the accuracy of the turbine pressure ratio map. Thus, the turbine temperature transient response may change somewhat in the future with the substitution of more precise maps.

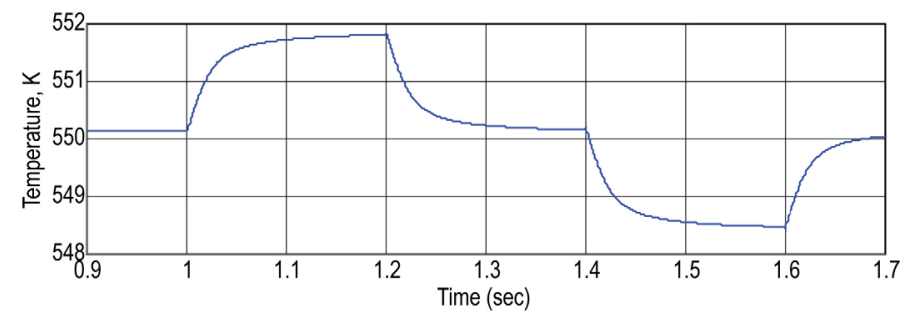

Figure 15.-Step response of compressor total temperature to engine input total temperature.

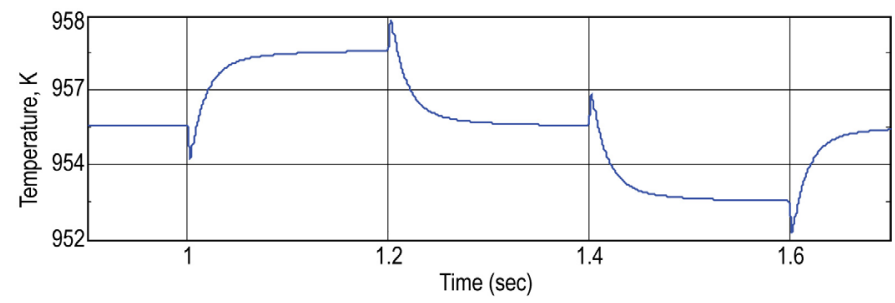

Figure 16.-Step response of turbine total temperature to engine input total temperature.

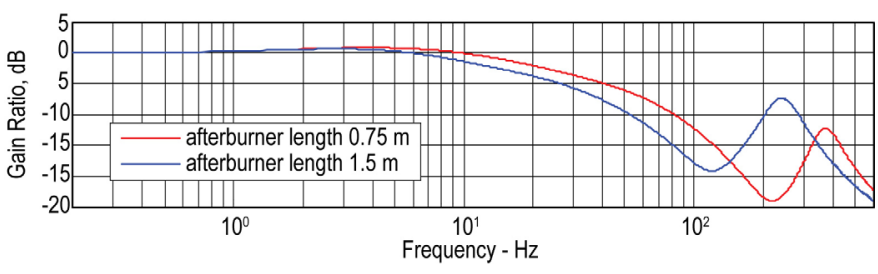

Figure 17.-Frequency response of engine thrust due to engine input total pressure with different afterburner lengths.

Figure 17 shows the TF of the thrust response due to the engine input total pressure for two cases; an afterburner length of $0.75 \mathrm{~m}$ and an afterburner length of $1.5 \mathrm{~m}$ (nominal). As seen in this figure, the effect of halving the afterburner length (halving its volume) is to shift the frequency response to the right, approximately double the frequency. This indicates that for this engine architecture, the afterburner dominates the frequency response due to its large volume in comparison with the rest of the engine components. These are preliminary results. But if these types of trends hold, it could mean that at least for the APSE supersonic engine studies a detailed stage-by-stage engine model may not be necessary.

\section{Future Plans}

In the future, the plan is as follows. For the engine, the plan is to further improve the engine model by incorporating more accurate information about its geometry and component performance maps as they become available. Develop a supersonic inlet 1-D finite element model in MATLAB that can be integrated to the rest of the engine simulation to arrive at an end-to-end integrated propulsion system simulation. Run analysis to find out whether a component level lumped volume dynamic model is accurate enough or if a stage-by-stage com- 
ponent model is needed. Assess the worst case disturbances for atmospheric wind gusts, pitch, yaw, and ASE modes excitation. Linearize the propulsion model and obtain TF for control design, design controls (ref. 8), and integrate the controls into the nonlinear propulsion system simulation. Analyze thrust variations of the propulsion system due to expected upstream flow field disturbances. From these thrust variation results, the ASE team would be assessing couplings to the vehicle ASE modes and impacts to flow field disturbances, upstream of the propulsion system. Finally, integrate the propulsion system with the vehicle ASE system model and refine the analyses of thrust variations, vehicle stability, and ride quality. As a separate effort, this relative high fidelity propulsion system simulation will be utilized to design improved control laws in order to increase the efficiency of the propulsion system.

The Supersonics Project may later provide an engine for testing and validation of the models. In case the engine does not become available, or does not become available in time, the plan is to bound the problem. It is anticipated that the frequency responses of the propulsion system, in terms of the dynamic frequencies, will be primarily influenced by the particular engine component geometries and those could possibly be estimated within an accuracy of few percent. The amplitudes of the responses would mainly be driven by the component performances, and these may also be estimated. Even though, the simulation results are rather sensitive to the accuracy of the engine component maps. Similarly, the analysis could be bounded for the expected worst case upstream atmospheric flow field disturbances and those flow disturbances that would be the result of excitations of vehicle ASE modes.

\section{Conclusion}

In this study a dynamic engine model is developed to enable studies of thrust variations due to upstream flow field disturbances, such as wind gusts, pitch, and yaw, as well as disturbances due to excitation of the vehicle aero-servo-elastic modes. Ultimately, the goal is to integrate the propulsion system simulation with the vehicle structural dynamic model to create an integrated vehicle aero-propulso-servo-elastic model that will enable integrated control design studies and studies involving vehicle stability and ride quality. Another, goal in developing this control volume dynamic model is to enable controls design to improve propulsion system performance and efficiency.

The engine component simulations are described in detail and pertinent results are given, including preliminary thrust variations due to the engine itself (i.e., without including the inlet at this point). Some comparative results are shown with previously published experimental data that validates the modeling approach. Enhancements to this engine model, in terms of more accurate geometry information and component performances are still in progress. The difficulty with these types of engine models is that more precise component performance maps and geometries are needed to achieve more accurate results and stable solutions. Future plans are also discussed that described the steps towards achieving an integrated aero-propulso-servo-elastic simulation to conduct the necessary research for supersonic vehicles.

\section{References}

1. Parker, K.I.; Guo, T.H.: "Development of a Turbofan Engine Simulation in Graphical Simulation Environment," NASA/TM-2003-212543.

2. Frederick, D.K.; DeCastro, J.A.; Litt, J.S.: 'User's Guide for the Commercial Modular Aero-Propulsion System Simulation (CMAPPS),"NASA/TM-2007-215026.

3. Kehoe, M.: "A Historical Overview of Flight Flutter Testing," NASA/TM-1995-4720.

4. Silva W.A.; Keller, D.F.; Florance, J.R.; Cole, S.R.; Scott, R.C.: "Experimental Steady and Unsteady Aerodynamic and Flutter Result for HSCT Semispan Models," AIAA Structural Dynamics, and Materials Conference and Exhibit, 41st, Atlanta, GA, Apr. 3-6, 2000, AIAA-2000-1697.

5. Seldner, K.; Mihaloew, J. R.; Blaha, R. J.: "Generalized Simulation Technique for Turbojet Engine System Analysis," NASA TN D-6610, February 1972.

6. Kopasakis, G.: "High Frequency Adaptive Instability Suppression Controls in a Liquid-Fueled Combustor," $39^{\text {th }}$ AIAA JPC, Huntsville, AL, July 2003, AIAA-2003-9581, NASA/TM2003-212535.

7. Hill, P.; Peterson, C.: "Mechanics and Thermodynamics of Propulsion," Addison Wesley Publication, $2^{\text {nd }}$ Edition, 1992.

8. Kopasakis G.: "Feedback Control Systems Loop Shaping Design with Practical Considerations," NASA/TM-2007-215007. 


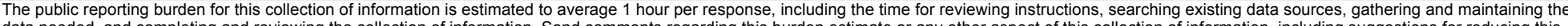

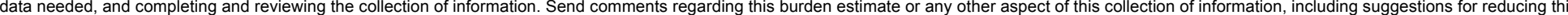

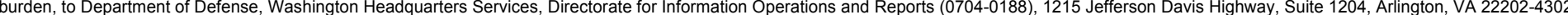

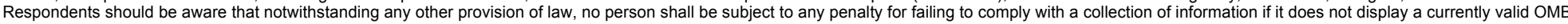
control number.

PLEASE DO NOT RETURN YOUR FORM TO THE ABOVE ADDRESS.

\section{REPORT DATE (DD-MM-YYYY) \\ 2. REPORT TYPE \\ 3. DATES COVERED (From - To)}

01-05-2008

\section{TITLE AND SUBTITLE}

Technical Memorandum

Volume Dynamics Propulsion System Modeling For Supersonics Vehicle Research

\section{5a. CONTRACT NUMBER}

5b. GRANT NUMBER

5c. PROGRAM ELEMENT NUMBER

6. AUTHOR(S)

Kopasakis, George; Connolly, Joseph, W.; Paxson, Daniel, E.; Ma, Peter

\section{5d. PROJECT NUMBER}

5e. TASK NUMBER

5f. WORK UNIT NUMBER

WBS 984754.02.07.03.20.02

8. PERFORMING ORGANIZATION REPORT NUMBER

E-16415

National Aeronautics and Space Administration

John H. Glenn Research Center at Lewis Field

Cleveland, Ohio 44135-3191

\section{SPONSORING/MONITORING AGENCY NAME(S) AND ADDRESS(ES)}

National Aeronautics and Space Administration

Washington, DC 20546-0001

10. SPONSORING/MONITORS
ACRONYM(S)
NASA
11. SPONSORING/MONITORING
REPORT NUMBER
NASA/TM-2008-215172

\section{DISTRIBUTION/AVAILABILITY STATEMENT}

Unclassified-Unlimited

Subject Categories: 01, 02, 07, and 08

Available electronically at http://gltrs.grc.nasa.gov

This publication is available from the NASA Center for AeroSpace Information, 301-621-0390

\section{SUPPLEMENTARY NOTES}

\section{ABSTRACT}

Under the NASA Fundamental Aeronautics Program, the Supersonics Project is working to overcome the obstacles to supersonic commercial flight. The proposed vehicles are long slim body aircraft with pronounced aero-servo-elastic modes. These modes can potentially couple with propulsion system dynamics; leading to performance challenges such as aircraft ride quality and stability. Other disturbances upstream of the engine generated from atmospheric wind gusts, angle of attack, and yaw can have similar effects. In addition, for optimal propulsion system performance, normal inlet-engine operations are required to be closer to compressor stall and inlet unstart. To study these phenomena an integrated model is needed that includes both airframe structural dynamics as well as the propulsion system dynamics. This paper covers the propulsion system component volume dynamics modeling of a turbojet engine that will be used for an integrated vehicle Aero-Propulso-Servo-Elastic model and for propulsion efficiency studies.

\section{SUBJECT TERMS}

Propulsion system modeling; Propulsion dynamics; Propulsion volume dynamics; Supersonics propulsion research

\begin{tabular}{|c|c|c|c|c|}
\hline \multicolumn{3}{|c|}{ 16. SECURITY CLASSIFICATION OF: } & \multirow{2}{*}{$\begin{array}{l}\text { 17. LIMITATION OF } \\
\text { ABSTRACT } \\
\text { UU }\end{array}$} & \multirow{2}{*}{$\begin{array}{l}\text { 18. NUMBER } \\
\text { OF } \\
\text { PAGES } \\
16\end{array}$} \\
\hline $\begin{array}{l}\text { a. REPORT } \\
\text { U }\end{array}$ & $\begin{array}{l}\text { b. ABSTRACT } \\
U\end{array}$ & $\begin{array}{l}\text { c. THIS } \\
\text { PAGE } \\
\text { U }\end{array}$ & & \\
\hline
\end{tabular}

19a. NAME OF RESPONSIBLE PERSON
STI Help Desk (email:help@ sti.nasa.gov)
19b. TELEPHONE NUMBER (include area code)
301-621-0390



